\title{
PATTERNS OF FUEL UTILIZATION BY THE THORACIC MUSCLES OF ADULT WORKER ANTS. THE USE OF LIPID BY A HYMENOPTERAN
}

\author{
M. M. Martin and T. J. LiEB \\ Division of Biological Sciences and Department of Chemistry, University of Michigan, \\ Ann Arbor, MI 48109, U.S.A.
}

(Received 9 March 1979)

\begin{abstract}
Patterns of fuel utilization in the thoracic muscles of three species of ants have been established.

2. The thoracic muscles of Formica ulkei exhibit a typical Hymenopteran metabolic organization, relying exclusively upon carbohydrate oxidation for the provision of metabolic energy. This species feeds upon honeydew.

3. Pogonomyrmex californicus, a granivorous ant, exhibits a metabolic organization unprecedented for a Hymenopteran species. Its thoracic energy metabolism is based upon lipid oxidation.

4. Atta colombica, a fungus feeder, can metabolize both carbohydrate and fat, a versatility which is not typical of Hymenoptera.

5 . It is concluded that patterns of fuel utilization in insects are not determined by phylogenetic inertia, but are selected to accommodate the activity patterns, feeding ecology and dietary regime of the species.
\end{abstract}

\section{INTRODUCTION}

Carbohydrates and lipids are the storage fuels most frequently utilized to sustain muscular activity. In insects it is generally recognized that there exist three common patterns of fuel utilization by flight muscle (Bailey, 1975; Crabtree \& Newsholme, 1975; Sacktor, 1975). Diptera and Hymenoptera sustain flight through the oxidation of carbohydrates, whereas flight metabolism in Lepidoptera is supported predominantly by the oxidation of fatty acids. Orthoptera are able to make efficient use of both carbohydrates and fats. In addition to these three common patterns of fuel utilization, a few insects have evolved a metabolic organization which exploits proline as a fuel for flight (Bursell et al., 1974; Hansford \& Johnson, 1975; Khan \& deKort, 1978).

Previous studies of patterns of fuel utilization in insects have emphasized phylogenetic correlations. However, it should be noted that the species which have been employed to establish phylogenetic correlates represent very different ecotypes. Thus, the carbohydrate specialists which ha'e been identified, all of which are Diptera and Hymenoptera, are species which feed frequently on nectar or other sugar solutions. The fat specialists, all of which are Lepidoptera, are all species which feed rarely if at all as adults, and which must survive on fuel reserves accumulated as larvae. Finally, the generalists capable of utilizing both carbohydrates and lipids, the Orthoptera, are voracious polyphagous species which are capable of long migratory flights.

This study explores patterns of fuel utilization in the thoracic musculature of three species of ants having very different dietary habits. Formica ulkei feeds extensively on honeydew, and therefore has a diet rich in carbohydrates and very low in lipid and protein. Pogonomyrmex californicus feeds on seeds, a resource which is particularly rich in lipids, and less rich in carbohydrates and protein. Atta colombica is a fungus-grower which subsists on the liquid contents of the mycelium of a symbiotic fungus. This fluid is rich in carbohydrates and protein, and low in lipids. Both $F$. ulkei and $P$. californicus also scavenge dead insects, but it is likely that this high-protein, high-lipid food is largely diverted to the developing brood (Lange, 1971).

The objective of this investigation was to establish whether all three of these ant species exhibit fuel utilization patterns typical of other Hymenoptera, or whether the organization of their energy metabolism might reflect their diverse dietary habits. The patterns of metabolic organization were established by determining the maximum activities of certain enzymes of constant proportion groups indicative of major metabolic pathways. The enzymes assayed were citrate synthase (CS, EC 4.1.3.7), glyceraldehydephosphate dehydrogenase (GAPDH, EC 1.2.1.12), 3-hydroxyacylCoA dehydrogenase (HOAD, EC 1.1.1.35), glycerophosphate dehydrogenase (GDH, EC 1.1.1.8) and lactate dehydrogenase (LDH, EC 1.1.1.27).

\section{MATERIAIS AND METHODS}

Insects

F. ulkei was collected in June from the E. S. George Reserve (Livingston County, Michigan). P. californicus was collected in July near Los Angeles (Orange County, California). A. colombica was taken from a captive colony maintained since 1969 in the Division of Biological Sciences of the University of Michigan. The colony originated in the Panama Canal Zone. 
Preparation of thoracic extracts

Between 50-100 thoraces, with legs attached, were homogenized by hand in a glass tissue grinder in about $4 \mathrm{ml}$ of cold, distilled-deionized water. The homogenate was centrifuged for $20 \mathrm{~min}\left(10,000 \mathrm{~g}, 4^{\circ} \mathrm{C}\right)$, the supernatant removed, the pellet resuspended in cold water and the centrifugation repeated. Supernatants were combined and the total volume was adjusted to $10 \mathrm{ml}$. Enzyme assays were conducted immediately following the preparation of the extracts.

Assays of enzyme activities

Activities in both the supernatant and pellet were assayed spectrophotometrically at $25^{\circ} \mathrm{C}$ using a doublebeam spectrophotometer with automatic recording of absorption against time. Most of the activity was in the supernatant fraction, but the activities reported are the summations of the activities in both the supernatant and pellet. Assay procedures for GAPDH, HOAD, GDH and LDH were adapted from Beenakkers (1969). CS activity was measured using a minor modification of the procedure of Srere (1969).

The assay mixtures had the following compositions: GAPDH: $0.05 \mathrm{M}$ TRA (triethanolamine)-HCl buffer (pH 7.6), $5 \mathrm{mM}$ EDTA (ethylenediaminetetracetic acid), $3.3 \mathrm{mM}$ $\mathrm{MgSO}_{4}, 0.15 \mathrm{mM} \mathrm{NADH}, 2.4 \mathrm{mM}$ reduced glutathione, $1.5 \mathrm{mM}$ ATP, $7 \mathrm{mM}$ 3-phosphoglycerate, 200 units phosphoglycerokinase; absorption recorded at $366 \mathrm{~nm}$. HOAD: $0.10 \mathrm{M}$ TRA-HCl buffer (pH 8.0), $5 \mathrm{mM}$ EDTA, $0.30 \mathrm{mM}$ $\mathrm{NADH}, 0.1 \mathrm{mM}$ acetoacetyl-CoA; absorption recorded at $366 \mathrm{~nm}$. GDH: $0.05 \mathrm{M}$ TRA- $\mathrm{HCl}$ buffer $(\mathrm{pH} 7.6), 5 \mathrm{mM}$ EDTA, $0.15 \mathrm{mM}$ NADH, $0.40 \mathrm{mM}$ dihydroxyacetone phosphate; absorption recorded at $366 \mathrm{~nm}$. LDH: $0.05 \mathrm{M}$ TRA-HCl buffer (pH 7.6), $5 \mathrm{mM}$ EDTA, $0.15 \mathrm{mM}$ NADH, $2.40 \mathrm{mM}$ pyruvate; absorption recorded at $366 \mathrm{~nm}$. CS: $0.10 \mathrm{M}$ TRA $-\mathrm{HCl}$ buffer (pH 8.0), $0.20 \mathrm{mM}$ DTNB [5,5'-dithiobis-(2-nitrobenzoic acid)] $0.50 \mathrm{mM}$ acety]-CoA, $0.50 \mathrm{mM}$ oxaloacetate; absorption recorded at $412 \mathrm{~nm}$.

\section{Protein determinations}

Protein content in the extracts was assayed using the protein-dye binding procedure of Bradford (1976). Reagents were supplied in the Bio-Rad Protein Assay Kit.

\section{RESULTS}

The levels of activity of the enzymes CS, GAPDH, HOAD, GDH and LDH are indicative of the relative contributions of the citric acid cycle, glycolysis, $\beta$-oxidation, the $\alpha$-glycerophosphate shuttle, and lactate fermentation, respectively, to the metabolism of a tissue. The activities of these five enzymes in the thoracic preparations of the three ant species $F$. ulkei, $P$. californicus and $A$. colombica are summarized in Table 1. Also included in Table 1 are the protein contents of the samples, information which allows the results to be recalculated in units of $\mu \mathrm{mol} / \mathrm{g}$ protein/ unit time. Muscle is the only tissue in the thorax with a high metabolic potential. About $50 \%$ of the volume is occupied by muscle, with most of the remaining space taken up by tracheae. Thus, the enzyme activity patterns obtained for these thoracic homogenates are determined by, and serve as indicators of, the composite enzyme profile of the thoracic musculature.

A direct comparison of the enzyme levels determined in this study with those reported in other investigations of insect muscles is complicated by the fact that we have had to use homogenates of entire thoraces, whereas most other studies report data on isolated, dissected muscle preparations. However, if the reasonable assumption is made that muscle constitutes between a quarter and a half of the thoracic mass, then it is evident that the enzyme levels in the ant muscles are considerably lower than the levels of the same enzymes in the flight muscles of appropriate comparison species (Beenakkers, 1969 Beenakkers et al., 1975; Alp et al., 1976). This is to be expected considering the lower energetic demands of walking compared to flying. Levels of CS activity in the ants' thoracic musculature appears to be comparable to those reported in the leg muscles of other insect species (Alp et al., 1976).

In Table 2, the enzyme ratios $\mathrm{GAPDH} / \mathrm{CS}$, $\mathrm{HOAD} / \mathrm{CS}, \mathrm{GAPDH} / \mathrm{HOAD}$ and GDH/CS for the ant species are summarized, along with the corresponding ratios for several other insect species with which comparisons will be made in the Discussion.

\section{DISCUSSION}

Of the three ant species investigated, $F$. ulkei has the biochemical profile most similar to that of other Hymenoptera. The metabolism of the thoracic muscles of this species is specialized for the exclusive use of carbohydrate. No HOAD activity could be detected in the thoraces of F. ulkei (Table 1), and the GAPDH/HOAD ratio, which indicates the relative commitments of a tissue to carbohydrate $v i s-a-a-v i s$ lipid metabolism, is large, having a value at least as large as 130 and probably larger (Table 2). Another indication of the reliance of $F$. ulkei on aerobic carbohydrate oxidation is the level of activity of GDH (indicative of the activity of the $\alpha$-glycerophosphate shuttle) and the GDH/CS ratio. The $\alpha$-glycerophosphate shuttle is crucial to an aerobic tissue which metabolizes carbohydrate to meet its energy needs,

Table 1. Enzyme activities in thoracic homogenates of F. ulkei, $P$. californicus and A. colombica*

\begin{tabular}{lccc}
\hline \multicolumn{1}{c}{ Enzyme (pathway) } & $\begin{array}{c}F . \text { ulkei } \\
\text { Mean (range) }\end{array}$ & $\begin{array}{c}\text { P. californicus } \\
\text { Mean (range) }\end{array}$ & $\begin{array}{c}\text { A. colombica } \\
\text { Mean (range) }\end{array}$ \\
\hline CS (citric acid cycle) & $32(30-34)$ & $15.3(14.5-16)$ & $10.5(9.5-11.5)$ \\
GAPDH (glycolysis) & $43(34-49)$ & $0.8(0.5-1.0)$ & $25(21-31)$ \\
HOAD ( $\beta$-oxidation) & None detected $\dagger$ & $3.1(2.6-3.4)$ & $1.4(0.9-1.7)$ \\
GDH ( $\alpha$-glycerophosphate shuttle) & $21(20-23)$ & $2.1(1.8-2.6)$ & $2.7(2.4-3.1)$ \\
LDH (lactate fermentation) & None detected $\dagger$ & $0.6(0.5-0.7)$ & None detected $\dagger$ \\
Milligrams protein/g fresh wt & $85(78-95)$ & $97(90-105)$ & $79(63-91)$ \\
\hline
\end{tabular}

* Activities expressed as $\mu \mathrm{mols} / \mathrm{g}$ fresh $\mathrm{wt} / \mathrm{min}$. Each value represents the mean of at least three experiments using different extracts.

† Minimum detectable activities: F. ulkei (HOAD, 0.4; LDH, 0.4); A. colombica (LDH, 0.7). 
Table 2. Enzyme activity ratios for $F$. ulkei, P. californicus and A. colombica and other selected insects*

\begin{tabular}{lcccc}
\hline \multicolumn{1}{c}{ Insect } & GAPDH:CS & HOAD:CS & GAPDH:HOAD & GDH:CS \\
\hline F. ulkei & 1.3 & $<0.01$ & $>130$ & 0.66 \\
P. californicus & 0.05 & 0.2 & 0.25 & 0.14 \\
A. colombica & 2.4 & 0.13 & 18 & 0.26 \\
A. mellifica (Hymenoptera) & 6.8 & 0.01 & 1500 & 1.3 \\
$P$. cynthia (Lepidoptera) & 0.20 & 1.2 & 0.2 & 0.15 \\
A. selene (Lepidoptera) & 0.25 & 2.1 & 1.0 & 0.17 \\
L. migratoria (Orthoptera) & 1.2 & 1.2 & 0.58 \\
\hline
\end{tabular}

* Ratios for A. mellifica and A. selene from Beenakkers (1969); ratios for P. cynthia and L. migratoria from Beenakkers et al. (1975).

but is less important to a lipid user, since the pathways of fatty acid oxidation do not result in the generation of cytoplasmic NADH. This ratio has a value of 0.66 in $F$. ulkei, somewhat less than the value of 1.3 observed in the honey bee, $A$. mellifica, but still considerably greater than the values of 0.15 and 0.17 observed in the lipid-utilizing moths, $P$. cynthia and A. selene.

Of the three ant species investigated, $F$. ulkei is the one with foraging and feeding habits most similar to those other Hymenoptera which have been studied. The adults of both $F$. ulkei and the honey bee feed frequently on sugar solutions (honeydew and nectar), while diverting high-protein, high-lipid food items (dead insects and pollen) to the developing brood. It would be counterproductive for an organism which feeds frequently on a high sugar diet to base its energy metabolism on the oxidation of fats synthesized from dietary carbohydrates. Although the cost of synthesizing $1 \mathrm{~mol}$ of esterified palmitic acid from $4.5 \mathrm{~mol}$ of glucose is less than $1 \mathrm{~mol}$ of ATP (assuming that 6 of the requisite 14 equivalents of NADPH are generated by the metabolism of $0.5 \mathrm{~mol}$ of glucose in the pentose cycle), there is still a considerable metabolic penalty associated with the conversion of sugar into fat. The potential yield of ATP from the oxidation of a mol of palmitate is only $80 \%$ of the yield which would be produced by the oxidation of the $4.5 \mathrm{~mol}$ of glucose required for the synthesis of the palmitate. Thus the transformation of carboydrate into fat results in the sacrifice of $20 \%$ of the fuel value of the dietary carbohydrate intake. For a honey bee or an ant, this sacrifice in fuel value would require a commitment of $20 \%$ additional time to foraging, a commitment which would require a drastic change in the activity patterns of these species. Clearly then, a resource utilization strategy involving frequent feeding on reliable, predictable, readily accessible sugar solutions is one which fosters the evolution of a specialized, carbohydrate based energy metabolism.

The harvester ant, $P$. californicus has a metabolic organization which is unprecedented for a Hymenopteran species. The low level of GAPDH and the low value of the GAPDH/CS ratio reveal an extraordinarily low glycolytic potential. The GAPDH/HOAD ratio of 0.25 is comparable to that of the two moths, $P$. cynthia and $A$. selene, which use fatty acids as their metabolic fuels. The GDH/CS ratio of 0.14 for $P$. californicus also closely approximates the values of 0.15 and 0.17 observed for the two aforementioned Lepidoptera. The presence in the thorax of LDH at a level nearly equal to that of GAPDH further emphasizes how much the biochemical profile of this species deviates from what has come to be regarded as a "typical" adult Hymenopteran pattern.

The lipid based energy metabolism of $P$. californicus is clearly an adaptation to diet. Since insects lack the biochemical capacity to convert lipids into carbohydrates a high-lipid diet would select for the capacity to utilize lipids as the metabolic fuel to support the high energy demands of locomotion. Indeed, it is difficult to envisage a carbohydrate-based energy metabolism in a species with a high-lipid, low-carbohydrate diet, and we suspect that future reports of lipid-using Hymenoptera, and possibly Diptera, only await the selection of suitable species for study

The biochemical profile of the thoraces of the fungus-grower, $A$. colombica, suggests that this species is able to support its locomotor activities by metabolizing either carbohydrate or lipid. Both GAPDH and HOAD are present at significant levels. The GAPDH/ HOAD ratio of 18 suggest a somewhat greater bias toward carbohydrate metabolism than is the case in $L$. migratoria, another species able to utilize either fuel. On the other hand, the low level of GDH activity and the comparatively low value of 0.26 for the $\mathrm{GDH} / \mathrm{CS}$ ratio suggest that this ant does not have a particularly active $\alpha$-glycerophosphate shuttle, a biochemical trait more typical of species which oxidize fats than of those which oxidize carbohydrates. It is interesting to note that while the thoracic muscles of $A$. colombica workers exhibit a metabolic versatility which is atypical of Hymenoptera, the flight muscles of males of the closely related species, A. sexdens, appear to conform to the more typical Hymenopteran pattern in that flight is powered entirely by the metabolism of carbohydrate reserves (Jutsum \& Quinlan, 1978).

One can only speculate upon the features of the diet and biology of $A$. colombica which have selected for the capacity of the workers to metabolize both carbohydrate and fat. The fungal fluid on which the ants feed has high nutritive value (Martin et al., 1969). It is the food of both the adults and the larvae, and probably provides the adults with amino acids and protein in excess of their needs. Since some amino acids are glucogenic and others are ketogenic, the transformation of protein into storage fuel must result in the synthesis of both carbohydrates and lipids. The efficient exploitation of protein surpluses, therefore, requires a capacity to utilize both classes of metabolic fuels. Thus it would seem reasonable to propose that it is the high nutritive quality of the diet of $A$. colom- 
bica which has selected for the metabolic versatility of this species.

The most striking feature of this study is that by examining only three species from the single Hymenopteran family, Formicidae, we have identified all three of the patterns of fuel utilization which, heretofore, have been discovered only by investigating diverse species from many different orders. From this we conclude that the nature of the fuel utilized by a given species to support its energy metabolism is not ordained by phylogenetic inertia, and is not uniform throughout each order. Rather it is a highly plastic trait which is shaped by the activity patterns, the feeding habits and the nutritional quality of the diet of the species.

Acknowledgements-We thank the Dpeartment of Chemistry for a Gomberg Summer Research Fellowship awarded to T.J.L. We thank Alex Mintzer for providing us with specimens of $P$. californicus and Joan Martin for technical assistance.

\section{REFERENCES}

Alp P. R., Newsholme E. A. \& Zammit V. A. (1976) Activities of citrate synthase and $\mathrm{NAD}^{+}$-linked and NADP ${ }^{+}$. linked isocitrate dehydrogenase in muscle from vertebrates and invertebrates. Biochem. J. 154, 689-700.

BAILeY E. (1978) Biochemistry of insect flight. Part 2. Fuel supply. In Insect Biochemistry and Function (Edited by Candy D. J. \& Kilby B. A.), pp. 89-176. Chapman \& Hall, London.

Beenakkers A. M. Th. (1969) Carbohydrate and fat as a fuel for insect flight. A comparative study. $J$. Insect Physiol. 15, 353-361.
Beenakkers A. M. Th., Van Den Broek A. Th. M. \& De Ronde Th. J. A. (1975) Development of catabolic pathways in insect flight muscles. A comparative study. J. Insect Physiol. 21, 849-859.

BRADFORD M. M. (1976) A rapid and sensitive method for the quantitation of microgram quantities of protein utilizing the principle of protein-dye binding. Analyt. Biochem. 72, 248-254.

Bursell E., Billing K. C., Hargrove J. W., McCabe, C. T. \& SlaCK E. (1974) Metabolism of the bloodmeal in tsetse flies. Acta trop. 31, 297-320

Crabtree B. \& Newsholme E. A. (1975) Comparative aspects of fuel utilization and metabolism by muscle In Insect Muscle (Edited by UsHeR wood P. N. R.), pp. 405-501. Academic Press, New York.

HANSFORD R. G. \& JoHNSON R. N. (1975) The nature and control of the tricarboxylate cycle in beetle flight muscle. Biochem. J. 148,, $389-402$.

Jutsum A. R. \& Quintan R. J. (1978) Flight and substrate utilization in laboratory-reared males of Atta sexdens. J. Insect Physiol. 24, 821-825.

Khan M. A. \& De KorT C. A. D. (1978) Further evidence for the significance of proline as a substrate for flight in the Colorado potato beetle, Leptinotarsa decemlineata. Comp. Biochem. Physiol. 60B, 407-411.

LANGE V. R. (1971) Die Nahrungsverteilung unter den Arbeiterinnen des Waldameisenstaates. Z. Tierpsychol. 24, 513-545.

Martin M. M., Carman R. M. \& MacConnell J. G. (1969) Nutrients derived from the fungus cultured by the fungus-growing ant Atta colombica tonsipes. Annls ent. Soc. Am. 62, 11-13.

SACKTOR B. (1975) Biochemistry of insect flight. Part 1 Utilization of fuels by muscle. In Insect Biochemistry and Function (Edited by CANDY D. J. \& Kilby B. A.), pp 3-88. Chapman \& Hall, London.

SRERE P. A. (1969) Citrate synthase. In Methods of Enzymo $\log$, Vol. 13 (Edited by Lowenstein J. M.), pp. 3-26. Academic Press, New York. 